\title{
"EMBRYOMA OF LUNG"
}

\author{
BY
}

\author{
W. G. BARNARD
}

St. Thomas's Hospital, London

(RECEIVED FOR PUblication MAY 12, 1952)

The chief interest of this case lies in the peculiar histology of the specimen and in the fact that the patient has had no further trouble attributable to the tumour since its removal in 1943.

\section{CASE Report}

Miss W., aged 40, had always been well until January, 1943. At that time she caught a "cold" which developed into "influenza," and this illness kept her in bed for about a fortnight. Convalescence was slow and she felt run down, but was eventually able to get back to her work. From this time she was troubled by a cough, which was productive and kept her awake at night, and by a feeling of heaviness in the front of the right chest. By April these symptoms had been aggravated by dyspnoea upon exertion and by a feeling of generalized and increasing weakness. Since the onset of her illness she had been bringing up sputum; at first this was frankly purulent and amounted to half a pint a day. With the coming of summer she felt a little better and the sputum diminished to an ounce in 24 hours.

At about this time she was referred by her doctor to a hospital in Exeter, where radiographs of the chest were made. These films showed a circumscribed

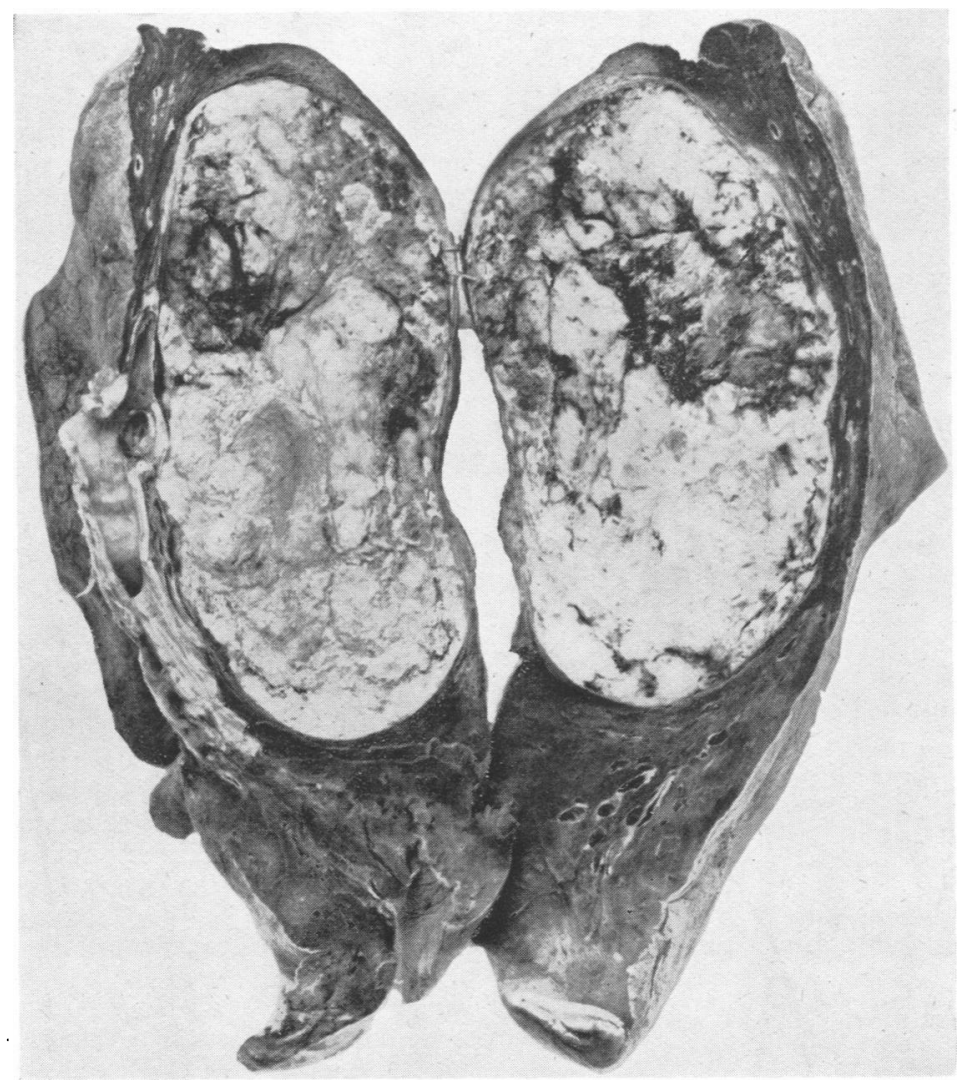

Fig. 1.-Fhotograph of specimen approximate'y half size. 


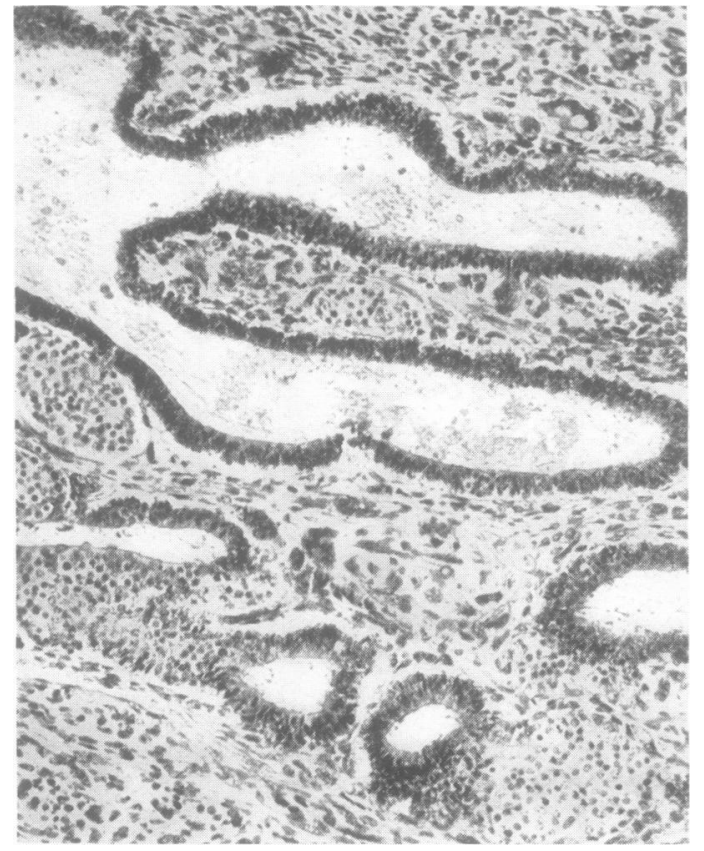

FIG. 2.-A low-power view ${ }^{*}$ showing multilayered columnar epithelium lining tubules, undifferentiated spindle and round cells surrounding the tubules, and islands of po'ygonal cells.

opacity of even density in the middle of the right lung; it was surrounded by lung tissue of normal appearance and was about as large as a small grapefruit.

The patient then came to London and was admitted to St. Thomas's Hospital under the care of Dr. Gardiner-Hill. Her general condition at that time was poor. Her temperature was normal, she

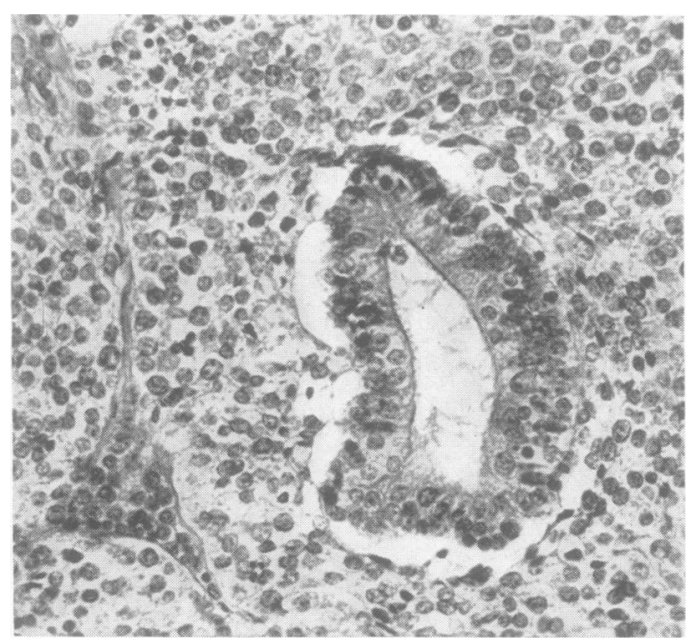

Fig. 4.-A single tubu'e surrounded by undifferentiated mesenchymal cells, the whole appearance being somewhat like developing lung.

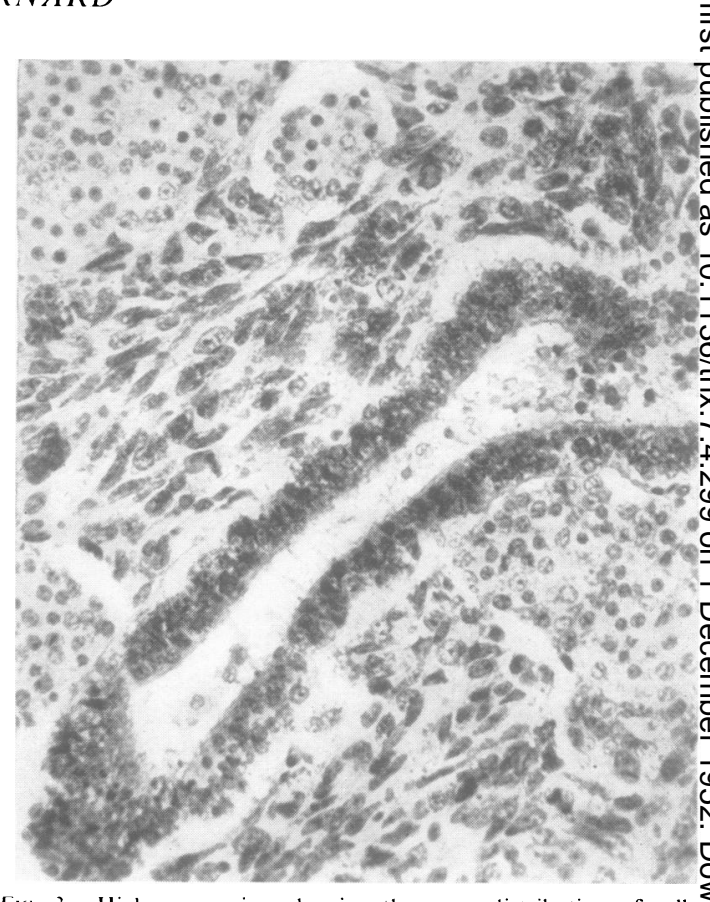

Fici. 3.-High-power view showing the same distribution of cells

had lost a great deal of weight, and was suffering from the effects of secondary anaemia. Her cough and sputum were still present, and the physical signs were dullness to percussion and absent breath-sounds over the middle thirds of the front and back of the chest. Antero-posterior and lateral radiographs were taken and showed an opacity similar to that which has already been described. The radiological diag-음 nosis suggested by these films was pulmonary hydatid $\underset{x}{\stackrel{一}{~}}$ cyst, and a Casoni reaction, which was negative, was $\dot{\sigma}$ done. The alternative diagnosis was a peripheral 3 . tumour of the lung.

The health of the patient was deteriorating rapidly $\frac{0}{3}$ and sputum was now blood-stained. Dr. Bamforth examined several specimens of sputum, but was un-음 able to find any malignant cells. It was at this stage that the patient volunteered the information that while in the West Country she had on one occa- $N$ sion coughed up a dark red object about the size of $\mathrm{F}$ her forefinger. Her doctor had recognized this object $N$ as a bronchial cast and had sent it to Exeter for $N$ examination. The report was blood-clot containing $\omega$ masses of malignant cells. Later on Dr. Bamforth was able to examine this slide himself and to confirm the above diagnosis. The patient was then trans- $\mathbb{D}$ ferred to Horton War Hospital for surgical treatment.?

On admission her condition was very poor, and, $\underset{T}{T}$ in addition to the state already described, she was irrational and most difficult to handle. A broncho- $\stackrel{\mathbb{Q}}{\Omega}$ scopy was done on August 17, 1943, under local $\overrightarrow{\mathbb{D}}$ anaesthesia, and nothing abnormal was detected in $\frac{\varrho}{\sigma}$ the bronchial tree. There was no evidence of metastases. 
On August 24, 1943, a dissection pneumonectomy was performed by Mr. Norman Barrett.

\section{Histological Report}

The tumour was oval, $12 \times 7 \times 7 \mathrm{~cm}$., felt solid, and was sharply circumscribed (Fig. 1). Its cut surface showed a firm, smooth, pinkish-grey tissue flecked with red, with opaque, yellowish-white, necrotic material scattered throughout it. Near the largest area of necrosis $(3 \times 2.5 \times 2 \mathrm{~cm}$. $)$ there was some haemorrhage. The lung in the periphery of the tumour was compressed, collapsed, and appeared to form a capsule for the tumour. On its median side the lung was reduced to less than $0.1 \mathrm{~cm}$.

On microscopical examination the tumour proved to be a mixed carcinoma and sarcoma of lung. The two types of tissue were closely mixed. The epithelial part in places produced tubes, or parts of tubes, lined with multilayered columnar epithelium resembling an immature bronchus (Figs. 2 and 3). In places there were papillae covered by similar epithelium and having a delicate fibrous tissue core. There were a few scattered groups of small polygonal cells very like those seen in one form of adenoma of bronchus. The connective tissue part varied from sheets of closely packed round or oval nuclei, with practically no cell outline or protoplasm, to spindle cells running in bands; some more mature cells were also present and these were producing fibre and gland cells.

In many places the epithelial-lined tubes were surrounded or partly surrounded by connective tissue cells very much like the arrangement of some embryomata of kidney. This arrangement and grouping also resemb!ed the bronchial buds growing into undifferentiated mesoderm in the developing lung of an embryo (Fig. 4). It is possible that the tumour had developed from a part of lung which had remained dormant and undeveloped, or that the tumour was recapitulating its own life history.

\section{COMMENT}

It might be argued that in spite of its peculiar histological appearance the tumour was benign. There were, however, parts of the periphery which suggested infiltration of lung and, as mentioned above, a piece of the tumour did in fact infiltrate a bronchus and was coughed up.

A brief description of this case appeared with others in the British Journal of Surgery $(32,447)$ under the heading "Some Unusual Thoracic Tumours," by N. R. Barrett and W. G. Barnard. 